\title{
Cost-effectiveness of twice-daily indacaterol/ glycopyrrolate inhalation powder for the treatment of moderate to severe COPD in the US
}

This article was published in the following Dove Press journal:

International Journal of COPD

\section{Krithika Rajagopalan' \\ Lisa Bloudek ${ }^{2}$ \\ Jessica $\mathrm{Marvel}^{3}$ \\ Carole Dembek' \\ Abhishek Kavati ${ }^{3}$}

'Sunovion Pharmaceuticals Inc., Marlborough, MA 01752, USA;

${ }^{2}$ Curta Inc., Seattle, WA 98II6, USA $;{ }^{3}$ Novartis Pharmaceuticals

Corporation, East Hanover,

NJ 07936, USA
Correspondence: Carole Dembek Sunovion Pharmaceuticals Inc. 84 Waterford Drive, Marlborough, MA 01752, USA

Tel +I 5083577704

Email carole.dembek@sunovion.com
Background: Indacaterol $27.5 \mu \mathrm{g} /$ glycopyrrolate $15.6 \mu \mathrm{g}$ (IND/GLY 27.5/15.6 $\mu \mathrm{g}$ ) inhalation powder, a twice-daily, fixed-dose combination of a long-acting beta2-agonist (LABA) and a long-acting antimuscarinic antagonist (LAMA), is indicated in the US for long-term maintenance treatment of airflow obstruction in patients with COPD. The safety and efficacy of IND/ GLY 27.5/15.6 $\mu \mathrm{g}$ have been established, but cost-effectiveness is not yet known. This study compared the cost-effectiveness of IND/GLY 27.5/15.6 $\mu \mathrm{g}$ with other long-acting COPD maintenance therapies.

Methods: A Markov model was constructed from the US payer perspective. Health states were defined as mild (post-bronchodilator $\mathrm{FEV}_{1} \geq 80 \%$ of predicted), moderate $\left(50 \% \leq \mathrm{FEV}_{1}<80 \%\right.$ of predicted), severe ( $30 \% \leq \mathrm{FEV}_{1}<50 \%$ of predicted), and very severe $\left(\mathrm{FEV}_{1}<30 \%\right.$ of predicted) COPD. Patients entering the model transitioned through health states based on placebo-adjusted change from baseline in trough $\mathrm{FEV}_{1}$ for each comparator at week 12. Comparators included other US Food and Drug Administration-approved LABA/LAMA fixed-dose combinations as well as commonly prescribed LAMA and LABA/inhaled corticosteroid agents. One-way and probabilistic sensitivity analyses were conducted to test the model assumptions and the overall robustness of the results.

Results: Using the model, IND/GLY 27.5/15.6 $\mu$ g treatment for 12 weeks resulted in total costs of US $\$ 23,375$ vs US $\$ 9,365$ for placebo. Compared with placebo, IND/GLY 27.5/15.6 treatment resulted in the highest improvement in $\mathrm{FEV}_{1}$ across all comparators and the lowest cost per decline in $100 \mathrm{~mL} \mathrm{FEV}_{1}$. IND/GLY 27.5/15.6 $\mu \mathrm{g}$ was also among the most costeffective treatment option as measured by St George's Respiratory Questionnaire response rate, at US $\$ 3,518$ per additional responder at 12 weeks compared with placebo. In addition, IND/GLY 27.5/15.6 $\mu \mathrm{g}$ had the lowest cost per severe exacerbation avoided vs placebo across all comparators (US \$87,686).

Conclusion: This model, developed from the US payer perspective with a 5-year time horizon, found IND/GLY 27.5/15.6 $\mu \mathrm{g}$ to be a cost-effective treatment option for patients with moderate to severe COPD.

Keywords: indacaterol, glycopyrrolate, cost-effectiveness, FEV , SGRQ, dual bronchodilation

\section{Introduction}

COPD is a progressive disease of the airways characterized by persistent airflow limitation, cough, dyspnea, and sputum production. ${ }^{1}$ In the US, COPD affects an estimated 30 million people ${ }^{2,3}$ and is the third leading cause of death. ${ }^{4,5}$ COPD contributes significantly to the total healthcare costs in the US, with national medical treatment 
costs projected to increase from $\$ 32.1$ billion in 2010 to $\$ 49.0$ billion by 2020 . In 2010 , total absenteeism costs attributable to COPD were $\$ 3.9$ billion, with an estimated 16.4 million days of work lost due to COPD. ${ }^{6}$ Furthermore, COPD is responsible for 1.5 million visits to the emergency room, more than 15 million physician visits, and 739,000 hospitalizations annually.

Current pharmacological treatments aim to control symptoms, reduce the frequency and severity of exacerbations, and improve exercise tolerance and overall health status. ${ }^{1}$ Inhaled long-acting bronchodilators are the mainstay of maintenance therapy in COPD, with long-acting beta ${ }_{2}$ /adrenergic receptor agonists (LABAs) and long-acting cholinergic/muscarinic antagonists (LAMAs) having been shown to significantly improve lung function, dyspnea, and health status, and lower exacerbation rates. ${ }^{1}$ Inhaled corticosteroids (ICS) may also be used in combination with LABA therapy for patients with a history of exacerbations despite appropriate treatment with long-acting bronchodilators. ${ }^{1}$ In addition, dual bronchodilation through LABA/LAMA combination therapy has been shown to improve lung function and patientreported outcomes compared with both LAMA and LABA monotherapies. ${ }^{9}$

Utibron $^{\circledR}$ Neohaler $^{\circledR}$ (indacaterol $27.5 \mu$ g/glycopyrrolate $15.6 \mu \mathrm{g}$ [IND/GLY 27.5/15.6 $\mu \mathrm{g}]$ ] inhalation powder is a twice-daily, fixed-dose combination of two long-acting bronchodilators, IND 27.5 $\mu \mathrm{g}$ (a LABA) and GLY 15.6 $\mu \mathrm{g}$ (a LAMA), indicated for the long-term maintenance treatment of airflow obstruction in patients with COPD in the US. ${ }^{10}$ The safety and efficacy of IND/GLY 27.5/15.6 $\mu \mathrm{g}$ were evaluated in the FLIGHT 1 and FLIGHT 2 trials, two replicate 12-week, multicenter, randomized, double-blind, parallel group, placebo- and active-controlled studies in patients with moderate to severe COPD ${ }^{11}$ In these studies, overall improvements in lung function, health-related quality of life, and symptoms were observed with IND/GLY $27.5 / 15.6$ compared with placebo and the monotherapies. It is important to note that outside the US, IND/GLY is available as a once-daily formulation of indacaterol $110 \mu \mathrm{g}$ and glycopyrronium $50 \mu \mathrm{g}$. As such, the findings from our analysis only apply to the US IND/GLY 27.5/15.6 $\mu \mathrm{g}$ formulation.

With the continuing emergence of innovative medical technologies that enhance patient outcomes, there has been a growing interest in the comparative cost-effectiveness of new drugs to understand their relative value. As the US moves toward a value-based healthcare system, cost-effectiveness analyses (ie, analysis of the relative cost and outcomes of two or more therapeutic options) are increasingly being used by formulary decision makers to better understand the tradeoffs involved in choosing between alternative interventions. While the safety and efficacy of IND/GLY 27.5/15.6 $\mu \mathrm{g}$ have been reported, its cost-effectiveness is not yet known. The purpose of this study was to model the 5-year costeffectiveness of IND/GLY 27.5/15.6 $\mu \mathrm{g}$ compared with other long-acting therapies used for maintenance treatment of moderate to severe COPD in the US.

\section{Methods \\ Model structure}

A Microsoft Excel ${ }^{\circledR}$-based Markov model was developed from the US payer perspective (Figure 1). Markov models are commonly used for the evaluation of interventions in chronic diseases to conceptualize different health states and transitions among these states. ${ }^{12}$

The model consisted of four health states, based on the classification of airflow limitation severity as defined in the 2017 Global Initiative for Chronic Obstructive Lung Disease report, ${ }^{1}$ and death. Health states were defined as: mild COPD (post-bronchodilator $\mathrm{FEV}_{1} \geq 80 \%$ of predicted), moderate COPD $\left(50 \% \leq \mathrm{FEV}_{1}<80 \%\right.$ of predicted $)$, severe COPD $\left(30 \% \leq \mathrm{FEV}_{1}<50 \%\right.$ of predicted), and very severe $\mathrm{COPD}\left(\mathrm{FEV}_{1}<30 \%\right.$ of predicted $){ }^{1}$ The model incorporated a 12-week cycle length, which is the standard timeframe for demonstration of efficacy in US COPD trials and the duration of the FLIGHT 1 and FLIGHT 2 trials. A time horizon of 5 years was chosen to balance the short-term perspective taken by many US-payer formulary decision makers against the need for a sufficiently long time horizon to capture rare events such as severe exacerbations.

A patient-level cohort was generated to determine the proportion of patients in each health state for each 12-week cycle. The cohort consisted of 1,000 patients with a mean (SD) $\mathrm{FEV}_{1}$ of $1.520 \pm 0.4771 / \mathrm{L}$ and mean (SD) percent predicted $\mathrm{FEV}_{1}$ of $54.9 \% \pm 13.3 \%$, assuming a normal distribution and censored at $30 \%$ and $80 \%$ to exclude mild and very severe patients, respectively. ${ }^{11}$ Consistent with baseline characteristics of the patients in FLIGHT 1 and FLIGHT 2, $67 \%$ of patients entered the model in the moderate COPD health state and $33 \%$ in the severe health state. ${ }^{11}$ The average age was 63.4 years and $63 \%$ were male.

Patients entering the model transitioned through health states based on placebo-adjusted change from baseline (CFB) in trough $\mathrm{FEV}_{1}$ for each comparator at week 12. After the initial improvement in lung function associated 


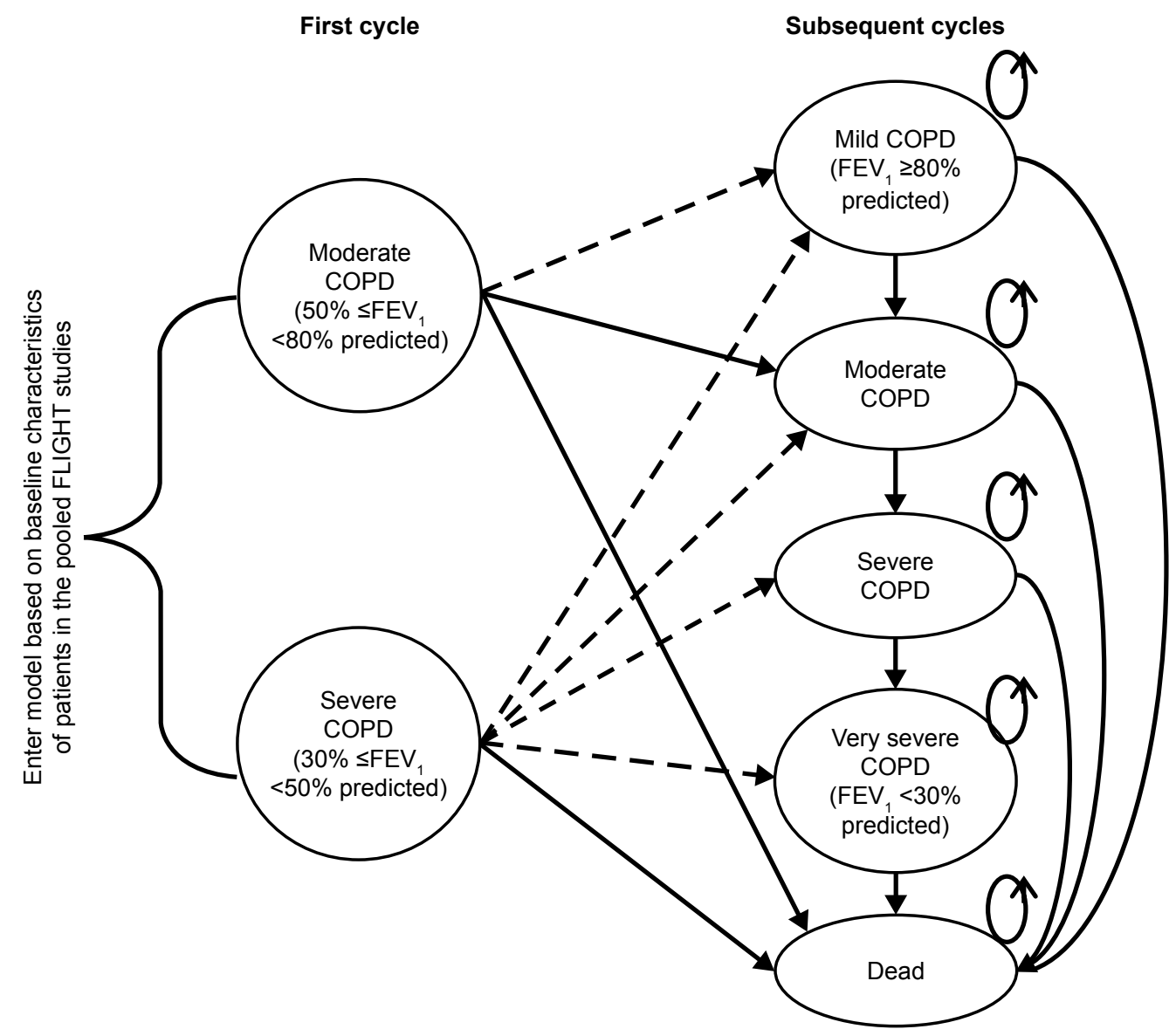

$-\mathbf{-}-\boldsymbol{\longrightarrow} \rightarrow$ Transitions representing improved lung function can occur only in the first cycle

Figure I Model structure.

with each treatment, patients were assumed to experience a stable rate of decline for the duration of the modeled time horizon. During each 12-week cycle, patients could remain in their health state, transition to the next more severe health state, or transition to death. All costs and outcomes were discounted at a rate of $3 \%$ per year and reported in 2017 US dollars (USD).

\section{Assumptions}

The following assumptions were made: 1) improvements in lung function occur only in the first cycle; 2) all patients would experience a stable rate of decline in predicted $\mathrm{FEV}_{1}$ beyond the first 12 -week cycle; 3 ) each health state was associated with a risk of non-severe and severe COPD exacerbations; 4) exacerbation outcomes were modeled based on a patient's underlying health state exacerbation risk; 5) exacerbations incurred additional costs and a temporary decline in health-related quality of life (health utility); and
6) all patients would receive treatment for the duration of the modeled time horizon with complete treatment adherence, no discontinuation, and no switching between products. Wholesale acquisition cost (WAC) was used for drug costs.

\section{Comparators}

The cost-effectiveness of IND/GLY 27.5/15.6 $\mu \mathrm{g}$ was compared with other US Food and Drug Administration-approved LABA/LAMA fixed-dose combination therapies: Anoro Ellipta $^{\circledR}$ (umeclidinium $62.5 \mu \mathrm{g}$ /vilanterol $25 \mu \mathrm{g}$ inhalation powder), ${ }^{13}$ Stiolto Respimat ${ }^{\mathbb{B}}$ (tiotropium bromide/olodaterol) inhalation spray, ${ }^{14}$ and Bevespi Aerosphere ${ }^{\circledR}$ (glycopyrrolate $9 \mu \mathrm{g} /$ formoterol fumarate $4.8 \mu \mathrm{g}$ ) inhalation aerosol. ${ }^{15}$ In addition, Spiriva Respimat ${ }^{\circledR}$ (tiotropium bromide) inhalation spray, a LAMA, and Advair Diskus ${ }^{\circledR}$ (fluticasone 250 $\mu \mathrm{g} / \mathrm{salmeterol} 50 \mu \mathrm{g}$ ) inhalation powder, a LABA/ICS, were included as comparators as both are commonly prescribed COPD maintenance therapies in the US. ${ }^{16}$ The results for 
IND/GLY 27.5/15.6 $\mu \mathrm{g}$ vs placebo were compared with the results of each comparator vs placebo.

\section{Model inputs}

Tables 1 and 2 provide an overview of all inputs used in the model. ${ }^{11,17-34}$

\section{Population}

Consistent with the baseline characteristics of patients in FLIGHT 1 and FLIGHT 2, patients in this analysis were $\geq 40$ years of age with moderate to severe COPD. Additional trial eligibility criteria included a smoking history of $\geq 10$ pack-years, post-bronchodilator $\mathrm{FEV}_{1}>30 \%$ and $<80 \%$ of predicted, and a post-bronchodilator $\mathrm{FEV}_{1} /$ FVC $<0.70$ at run-in. Trial exclusion criteria included patients with clinically significant renal or cardiovascular disease, malignancies, history of asthma, and COPD exacerbation that required antibiotics and/or systemic corticosteroids and/or hospitalization in the prior 6 weeks.

\section{Treatment efficacy}

The model incorporated several effectiveness measures including COPD-specific measures such as $\mathrm{FEV}_{1}$ decline avoided, St George's Respiratory Questionnaire (SGRQ) responder gained, and severe and non-severe exacerbation avoided. Other effectiveness measures included life-years (LYs) gained and quality-adjusted life-years (QALYs) gained.

\section{Lung function}

CFB in trough $\mathrm{FEV}_{1}$ was obtained from the pivotal trials of IND/GLY 27.5/15.6 $\mu \mathrm{g}$ and each comparator vs placebo at week 12 (Table 2). ${ }^{11,15,17,20-22,25,28,35-39}$

\section{SGRQ}

SGRQ responders, the proportion of patients achieving the minimal clinically important difference in SGRQ total score at week 12 for each comparator, were obtained from publications and prescribing information (Table 2). ${ }^{40}$ The SGRQ

Table I Population and health-state inputs

\begin{tabular}{|c|c|c|}
\hline Parameter & Value & Reference \\
\hline Discount rate for costs & $3.0 \%$ & Assumption \\
\hline Discount rate for outcomes & $3.0 \%$ & Assumption \\
\hline Mean (SD) FEV, at baseline & $1.520(0.477 \mid)$ & 26 \\
\hline Mean (SD) percentage predicted FEV, at baseline & $54.9 \%(13.3 \%)$ & 26 \\
\hline Annual absolute rate of decline in percentage predicted $\mathrm{FEV}_{\text {, }}$ & $-1.0 \%$ & 19 \\
\hline \multicolumn{3}{|l|}{ Utility } \\
\hline Mild & 0.8971 & 18 \\
\hline Moderate & 0.7551 & 18 \\
\hline Severe & 0.7481 & 18 \\
\hline Very severe & 0.5493 & 18 \\
\hline \multicolumn{3}{|l|}{ Probability of mortality per cycle } \\
\hline Mild & $0.276 \%$ & 27 \\
\hline Moderate & $0.276 \%$ & 27 \\
\hline Severe & $0.551 \%$ & 27 \\
\hline Very severe & $2.19 \%$ & 27 \\
\hline \multicolumn{3}{|l|}{ Rate of non-severe exacerbations per cycle } \\
\hline Mild & 0.17 & 25 \\
\hline Moderate & 0.17 & 25 \\
\hline Severe & 0.25 & 25 \\
\hline Very severe & 0.34 & 25 \\
\hline \multicolumn{3}{|l|}{ Rate of severe exacerbations per cycle } \\
\hline Mild & 0.03 & 24 \\
\hline Moderate & 0.03 & 24 \\
\hline Severe & 0.06 & 24 \\
\hline Very severe & 0.12 & 24 \\
\hline Length of a non-severe exacerbation & 14 days & 23 \\
\hline Length of a severe exacerbation & 28 days & 23 \\
\hline Utility decline associated with a non-severe exacerbation & $15 \%$ & 31 \\
\hline Utility decline associated with a severe exacerbation & $50 \%$ & 31 \\
\hline Cost associated with a non-severe exacerbation & $\$ 301$ & $\mathrm{I}, 23,29,30,33,34$ \\
\hline Cost associated with a severe exacerbation & $\$ 10,343$ & $\mathrm{I}, 23,29,30,33,34$ \\
\hline Cost per pneumonia episode & $\$ 5,240$ & 32 \\
\hline
\end{tabular}


Table 2 Comparator-specific inputs

\begin{tabular}{|c|c|c|c|c|c|c|c|}
\hline \multirow[t]{2}{*}{ Comparator } & \multicolumn{2}{|c|}{$\begin{array}{l}\text { Difference from placebo } \\
\text { in mean CFB to week } 12 \\
\text { in FEV }\end{array}$} & \multirow{2}{*}{\begin{tabular}{|l|} 
WAC per \\
30 days $^{33}$
\end{tabular}} & \multicolumn{2}{|c|}{$\begin{array}{l}\text { I2-week probability of } \\
\text { pneumonia episode }\end{array}$} & \multicolumn{2}{|c|}{$\begin{array}{l}\text { Difference from placebo } \\
\text { SGRQ response rate at } \\
\text { I } 2 \text { weeks }\end{array}$} \\
\hline & Value & Reference & & Value (\%) & Reference & Value (\%) & Reference \\
\hline Indacaterol/glycopyrrolate & 0.223 & 11 & $\$ 340.20$ & 0.0 & 11 & 21.4 & 11 \\
\hline Tiotropium bromide/olodaterol & 0.164 & 28 & $\$ 340.93$ & 0.8 & 15 & 20.6 & 28 \\
\hline Tiotropium & 0.110 & 25 & $\$ 368.20$ & 0.0 & 35 & 18.5 & 25 \\
\hline Fluticasone/salmeterol & 0.160 & 20 & $\$ 361.40$ & 1.6 & 36 & No data & 20 \\
\hline Budesonide/formoterol & 0.090 & 20 & $\$ 308.68$ & 0.9 & 37 & No data & 20 \\
\hline Aclidinium & 0.110 & 25 & $\$ 322.17$ & 0.0 & 38 & 10.3 & 25 \\
\hline Fluticasone/vilanterol & 0.199 & 22 & $\$ 321.74$ & 1.4 & 39 & No data & 22 \\
\hline Umeclidinium/vilanterol & 0.195 & 21 & $\$ 340.93$ & 0.0 & 21 & 8.0 & 21 \\
\hline Glycopyrrolate/formoterol & 0.127 & 17 & $\$ 334.62$ & 0.0 & 17 & 11.0 & 17 \\
\hline Placebo & 0.000 & $N / A$ & $\$ 0.00$ & 0.0 & $\mathrm{~N} / \mathrm{A}$ & 0.0 & N/A \\
\hline
\end{tabular}

Note: All costs are presented in USD (2017).

Abbreviations: CFB, change from baseline; N/A, not applicable; SGRQ, St George's Respiratory Questionnaire; WAC, wholesale acquisition cost.

responder rate was taken as an average of the responder rates at week 12 in the FLIGHT 1 (57\% for IND/GLY 27.5/15.6 $\mu \mathrm{g}$ vs 39\% for placebo) and FLIGHT 2 (59.2\% for IND/GLY $27.5 / 15.6 \mu \mathrm{g}$ vs $34.5 \%$ for placebo) studies. The CFB in $\mathrm{FEV}_{1}$ total score and SGRQ response rates for each comparator were subtracted from placebo or the trial comparator to adjust for differences in study design and patient population.

\section{Rate of exacerbations}

Each health state was associated with a rate of non-severe and severe exacerbations (Table 1). Monthly probabilities of exacerbations were estimated from the literature ${ }^{27}$ and adjusted to 12-week rates, assuming a constant exacerbation rate. Based on previous models, ${ }^{16,24}$ the rate of non-severe and severe COPD exacerbations per health state was assumed to be 0.17 and 0.03 for moderate COPD, 0.25 and 0.06 for severe COPD, and 0.34 and 0.12 for very severe COPD, respectively, per 12 weeks. ${ }^{16,24}$ As the rate for the mild COPD health state was not available, these rates were assumed to be the same as for moderate COPD. ${ }^{25}$

\section{Rate of adverse events}

Pneumonia was included in the model as a potentially costly adverse event that has been associated with some comparators. ${ }^{11,15}$ The rate of pneumonia for each comparator was obtained from its respective product labeling and/or clinical trials and adjusted to a 12-week cycle length (Table 2). If no pneumonia events were listed in the available published study information, the rate was assumed to be zero.

\section{Other model inputs}

\section{Mortality}

Each health state was associated with a risk of death (Table 1). All values were based on the monthly probability of mortality per health state reported in literature ${ }^{27}$ and adjusted to 12-week cycles assuming a constant mortality rate. The 12-week probability of death, by COPD health state, was assumed to be $0.276 \%$ for mild and moderate COPD, $0.551 \%$ for severe COPD, and $2.19 \%$ for very severe COPD.

\section{Utilities}

Utilities are a measure of patient preference for health states and range from 0 (death) to 1 (perfect health) (Table 1). Health state utility values were obtained from published estimates ( 0.8971 for mild, 0.7551 for moderate, 0.7481 for severe, and 0.5493 for very severe health states). ${ }^{18}$ Utility values were used to calculate QALYs gained by multiplying the number of accrued LYs in each health state by the corresponding health state utility.

COPD exacerbations were associated with a temporary decline in utility: non-severe exacerbations with a $15 \%$ decline lasting 14 days, and severe exacerbations with a $50 \%$ decline lasting 28 days. ${ }^{31}$ Following the temporary decline, the utility values for each health state were assumed to revert back to their previous value for the remainder of time in the 12-week cycle.

\section{Cost measures}

\section{Drug costs}

Drug utilization was based on the strength and frequency of administration contained in respective product labeling (Table 2). Drug costs were based on WAC (per Red Book 2017). ${ }^{33}$ The base-case analysis assumed a $\$ 50$ patient copay per prescription to approximate Tier 3 non-preferred brand status with no discounts for any products. ${ }^{41}$

\section{Medical costs}

Additional costs included those of non-severe and severe COPD exacerbations. Non-severe exacerbations were 
assumed to be treated on an outpatient basis, while severe exacerbations were assumed to require hospitalization. The total cost of an exacerbation was calculated as the proportion of patients using health resources as a result of the exacerbation, multiplied by the unit cost per type of health resource. The cost associated with managing each exacerbation episode was estimated at $\$ 301$ for non-severe exacerbations and $\$ 10,343$ for severe exacerbations. ${ }^{19}$

\section{Other costs}

Each case of pneumonia was associated with an additional cost of $\$ 5,240$ per episode per 12 weeks. This cost per episode was based on an additional cost of $\$ 17,039$ (2007 USD), which was inflated to 2017 USD using the medical care component of the Bureau of Labor Statistics Consumer Price Index and then converted to 12 weeks, assuming 52.1 weeks in a year. ${ }^{32,42}$

\section{Model calculations}

The model reported total costs, change in $\mathrm{FEV}_{1}$, SGRQ responder rates, exacerbations, adverse events, total LYs gained, and total QALYs gained. The cost-effectiveness of IND/GLY $27.5 / 15.6 \mu \mathrm{g}$ or a comparator vs placebo was determined by calculating the incremental total cost per unit effectiveness gained: $(\mathrm{Ci}-\mathrm{Cs}) /(\mathrm{Ei}-\mathrm{Es})$, where $\mathrm{Ci}$ is the cost accrued by the treatment of interest, $\mathrm{Cs}$ is the cost accrued by placebo, Ei is the effectiveness accrued by the treatment of interest, and Es is the effectiveness accrued by placebo.

\section{Model uncertainty}

Both one-way and probabilistic sensitivity analyses (PSA) were conducted to test the assumptions of the model and the overall robustness of the results. The effect of varying individual parameters $( \pm 10 \%)$ on model outcomes was examined in one-way sensitivity analyses (OWSA) with each input being ranked from the most to least sensitive and plotted on a tornado diagram. For the PSA (second-order Monte Carlo simulation), in which all parameters in the model were varied simultaneously, distributions were stochastically sampled for 1,000 iterations and results shown on a cost-effectiveness plane, where incremental costs and incremental QALYs were plotted as a scatter plot.

\section{Results}

In this 5-year cost-effectiveness model, treatment with IND/ GLY 27.5/15.6 $\mu \mathrm{g}$ resulted in total costs of $\$ 23,375$ compared with $\$ 9,365$ for placebo. Total costs for comparators ranged from $\$ 23,016$ for aclidinium bromide $400 \mu \mathrm{g}$ inhalation powder to $\$ 26,499$ for fluticasone propionate $250 \mu \mathrm{g}$ and salmeterol $50 \mu \mathrm{g}$ inhalation powder (Table 3).

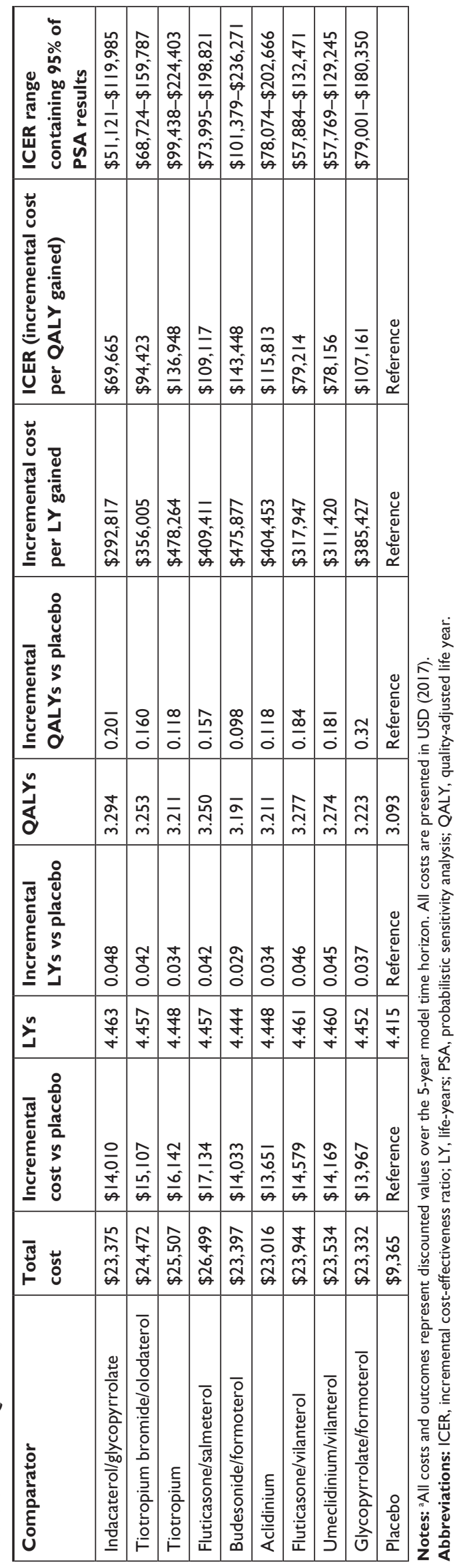


Table 4 COPD-specific results ${ }^{\mathrm{a}}$

\begin{tabular}{|c|c|c|c|c|}
\hline Comparator & $\begin{array}{l}\text { Incremental cost per } \\
100 \mathrm{~mL} \text { decline in } \\
\text { FEV , avoided }\end{array}$ & $\begin{array}{l}\text { Incremental I } 2 \text {-week cost } \\
\text { per SGRQ responder } \\
\text { gained at I } 2 \text { weeks }\end{array}$ & $\begin{array}{l}\text { Incremental cost per } \\
\text { severe exacerbation } \\
\text { avoided }\end{array}$ & $\begin{array}{l}\text { Incremental cost } \\
\text { per AE pneumonia } \\
\text { episode avoided }\end{array}$ \\
\hline Indacaterol/glycopyrrolate & $\$ 290$ & $\$ 3,518$ & $\$ 87,686$ & Equal $\mathrm{AEs} \mathrm{s}^{\mathrm{b}}$ \\
\hline Tiotropium bromide/olodaterol & $\$ 425$ & $\$ 3,906$ & $\$ 113,218$ & Dominated \\
\hline Tiotropium & $\$ 677$ & $\$ 4,602$ & $\$ 163,270$ & Equal $\mathrm{AEs}{ }^{\mathrm{b}}$ \\
\hline Fluticasone/salmeterol & $\$ 494$ & a & $\$ 130,759$ & Dominated \\
\hline Budesonide/formoterol & $\$ 720$ & a & $\$ 166,307$ & Dominated \\
\hline Aclidinium & $\$ 573$ & $\$ 7,023$ & $\$ 138,072$ & Equal $\mathrm{AEs}{ }^{\mathrm{b}}$ \\
\hline Fluticasone/vilanterol & $\$ 338$ & a & $\$ 97,177$ & Dominated \\
\hline Umeclidinium/vilanterol & $\$ 335$ & $\$ 9,481$ & $\$ 95,645$ & Equal $\mathrm{AEs}{ }^{\mathrm{b}}$ \\
\hline Glycopyrrolate/formoterol & $\$ 519$ & $\$ 6,862$ & $\$ 129,082$ & Equal $A E s^{b}$ \\
\hline Placebo & Reference & Reference & Reference & Reference \\
\hline
\end{tabular}

Notes: aSGRQ data not available at the time of analysis. ${ }^{b}$ Assumed no higher rate of pneumonia on treatment vs placebo. Dominated, higher rate of pneumonia vs placebo and higher cost vs placebo. All costs are presented in USD (2017).

Abbreviations: AE, adverse event; SGRQ, St George's Respiratory Questionnaire.

\section{COPD-specific results}

Compared with placebo, treatment with IND/GLY 27.5/15.6 resulted in the highest improvement in $\mathrm{FEV}_{1}$ across all comparators and the lowest cost per decline in $100 \mathrm{~mL}$ $\mathrm{FEV}_{1}$ avoided. IND/GLY 27.5/15.6 $\mu \mathrm{g}$ was also among the most cost-effective treatment options as measured by SGRQ responder rate, at $\$ 3,518$ per additional responder at 12 weeks compared with placebo (Table 4). In addition, IND/ GLY 27.5/15.6 $\mu \mathrm{g}$ had the lowest cost per severe exacerbation avoided vs placebo across all comparators $(\$ 87,686)$ (Table 4). Results for adverse events avoided were similar.

\section{LY and QALY results}

Treatment with IND/GLY 27.5/15.6 $\mu \mathrm{g}$ resulted in a total of 4.463 LYs and 3.294 QALYs gained compared with 4.415 LYs and 3.093 QALYs for placebo (Table 3). The cost/LY and cost/QALY of IND/GLY 27.5/15.6 $\mu \mathrm{g}$ compared with placebo was $\$ 292,817 / \mathrm{LY}$ and $\$ 69,665 / \mathrm{QALY}$, which was more cost-effective than any comparators vs placebo.

Results from the OWSA for the outcome of incremental cost per QALY for IND/GLY 27.5/15.6 $\mu \mathrm{g}$ vs placebo showed that the model parameters with the greatest influence on the model results were related health state utility values, followed by the cost of IND/GLY 27.5/15.6 $\mu \mathrm{g}$, followed by exacerbation rates and treatment efficacy as measured by change in $\mathrm{FEV}_{1}$ (Figure 2). Results of the PSA demonstrated that IND/GLY 27.5/15.6 $\mu \mathrm{g}$ has a high probability of being cost-effective compared with alternative COPD maintenance therapies over a 5-year time horizon, with 95\% of incremental cost-effectiveness ratios (ICERs) calculated based on the PSA falling between $\$ 51,121$ and $\$ 119,985$ per QALY gained (Table 3; Figure 3). Based on the results of 1,000 model iterations, IND/GLY 27.5/15.6 $\mu \mathrm{g}$ has a $99 \%$ chance of being cost-effective at a willingness-to-pay of $\$ 150,000$ per QALY gained and $93 \%$ at a willingness-to-pay of $\$ 100,000$ per QALY gained over placebo.

\section{Discussion}

In the present analysis, IND/GLY 27.5/15.6 $\mu \mathrm{g}$ was found to be a cost-effective treatment option for patients with moderate to severe COPD. Over 5 years, the total costs associated with IND/GLY 27.5/15.6 $\mu \mathrm{g}$ were lower than all comparators except glycopyrrolate $9 \mu \mathrm{g}$ /formoterol fumarate $4.8 \mu \mathrm{g}$ inhalation aerosol, with improved outcomes vs all comparators. The greater $\mathrm{CFB}$ in $\mathrm{FEV}_{1}$ observed with IND/ GLY 27.5/15.6 $\mu \mathrm{g}$ vs comparators translated into a larger proportion of time spent in the less severe COPD health states and less time spent in more severe health states for patients treated with IND/GLY 27.5/15.6 $\mu \mathrm{g}$.

Outside the US, government health authorities routinely use defined cost/QALY thresholds to determine whether a drug has adequate economic value for reimbursement. ${ }^{43}$ While formal thresholds do not exist in the US, several recently developed value frameworks incorporate cost-effectiveness analyses with specific dollar thresholds to determine the economic value of drugs and other healthcare services. The framework developed by the American College of Cardiology and the American Heart Association (ACC/AHA) places interventions into three categories: high value $=$ ICER $<$ US $\$ 50,000 /$ QALY; intermediate value $=$ ICER US $\$ 50,000$ 150,000/QALY; and low value $=$ ICER > US $\$ 150,000 /$ QALY. The value framework developed by the Institute for Clinical and Economic Review considers therapies with a cost/QALY ranging from US $\$ 50,000-100,000 /$ QALY to have high value. Applying these thresholds to the results of our cost-effectiveness assessment, IND/GLY 27.5/15.6 $\mu \mathrm{g}$ 


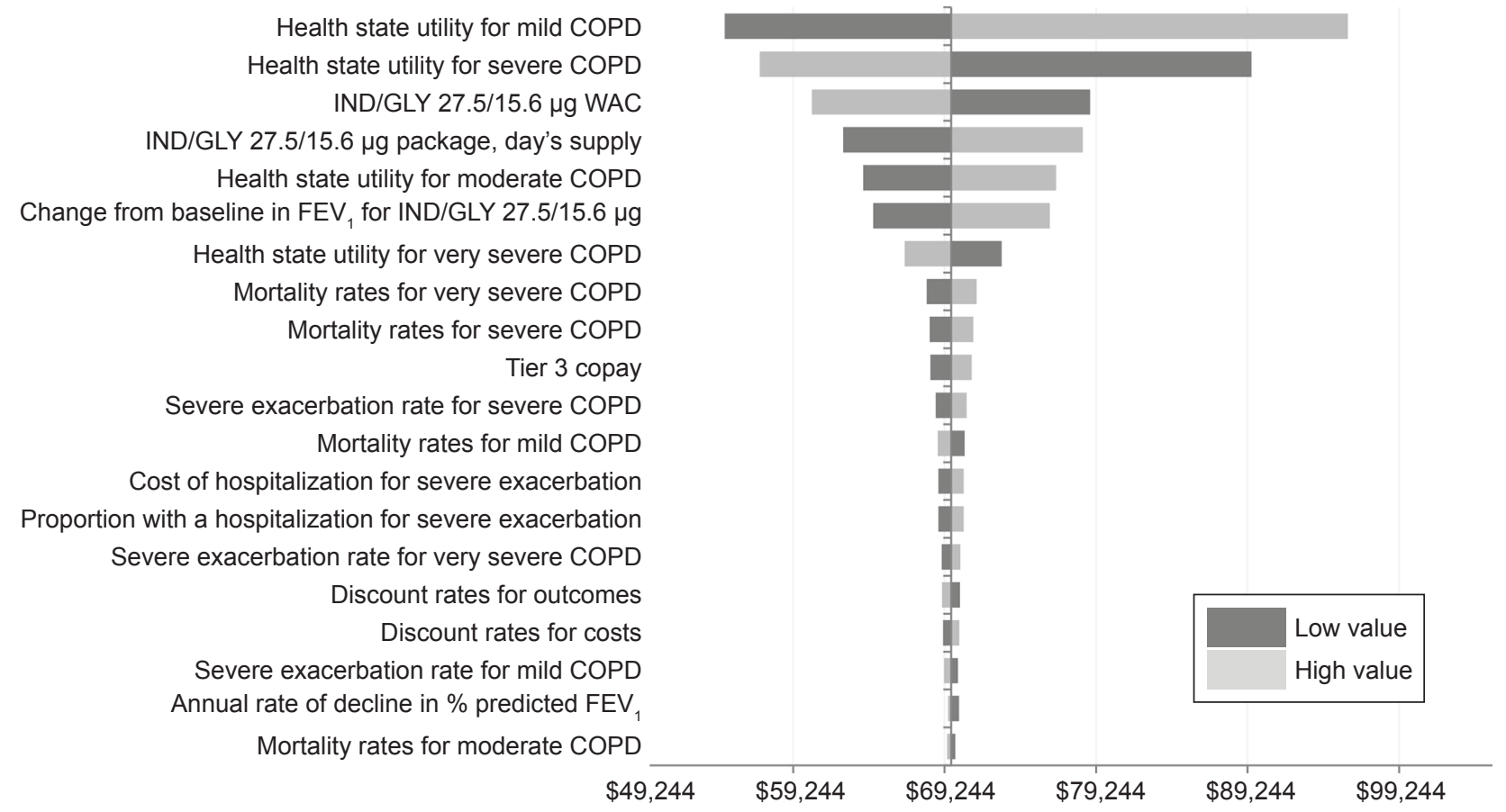

Figure 2 OWSA tornado chart for cost per QALY gained for IND/GLY 27.5/I5.6 $\mu \mathrm{g}$ vs placebo. ${ }^{2}$

Notes: a Chart limited to the top 20 most influential parameters. All costs are presented in USD (2017).

Abbreviations: GLY, glycopyrrolate; IND, indacaterol; OWSA, one-way sensitivity analysis; QALY, quality-adjusted life year; WAC, wholesale acquisition cost.

and comparators would be considered to have intermediate value according to ACC/AHA and high value according to the Institute for Clinical and Economic Review.

A search of the peer-reviewed literature revealed that few COPD cost-effectiveness analyses were reported from the perspective of a US payer. To the authors' knowledge, it appears that this model is the first to compare the cost-effectiveness of a LABA/LAMA fixed-dose combination with other LABA/ LAMA fixed-dose combinations in the US. A recent study reported findings from a US analysis of umeclidinium/vilanterol for the treatment of patients with moderate to very severe COPD ${ }^{16}$ The model structure and health states were similar to this model with a longer time horizon of 20 years. The model compared the cost-effectiveness of umeclidinium/vilanterol to tiotropium, open combinations of LABA and LAMA therapies, and placebo. Umeclidinium/vilanterol was found to be lower in cost and more effective (dominant) than tiotropium and placebo for cost/LYs gained and cost/QALYs gained and

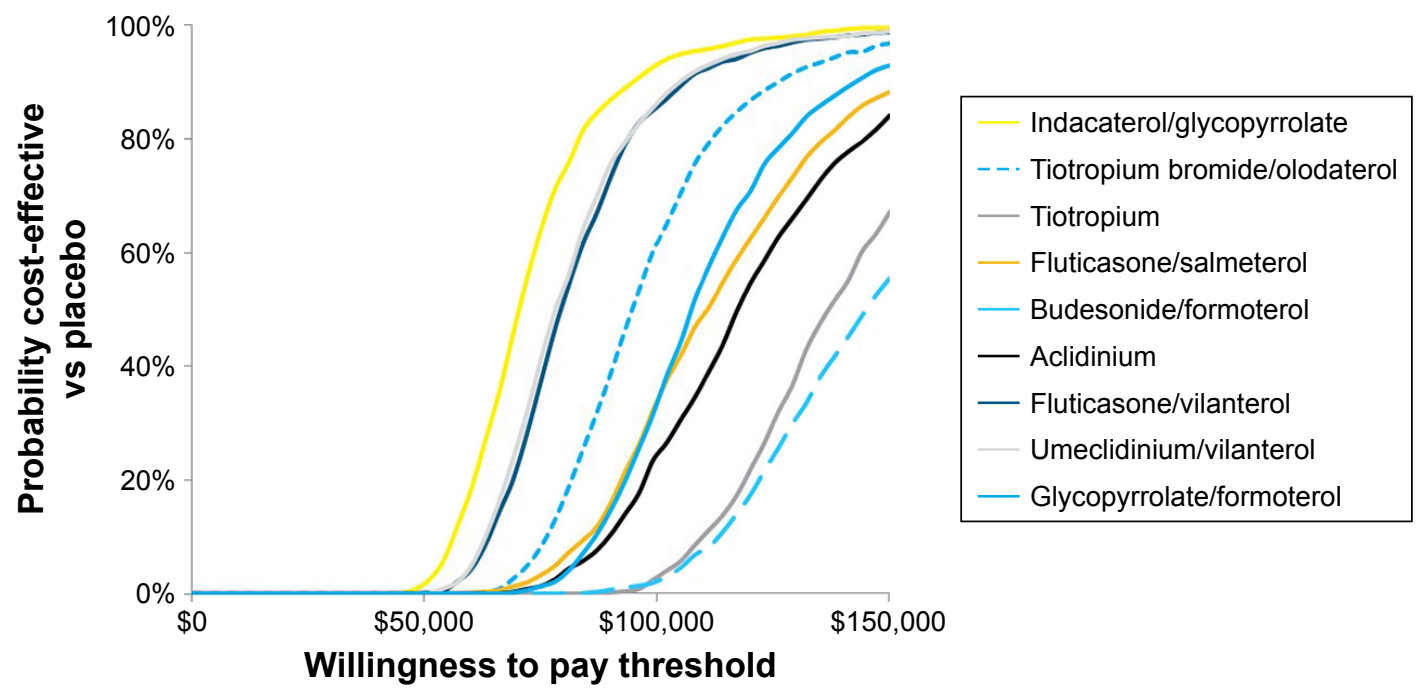

Figure 3 Cost-effectiveness acceptability curve. Note: All costs are presented in USD (2017). 
lower in cost than open combinations of LABA and LAMA therapies. Similarly, this model found IND/GLY 27.5/15.6 $\mu \mathrm{g}$ to be dominant to tiotropium in terms of cost/QALYs, cost/ exacerbation-avoided, and cost/SGRQ responder.

This model has a number of strengths. Due to the chronic nature of COPD and the long-term effects of the condition, the implementation of a Markov model and a 5-year time horizon allows the long-term assessment of cost-effectiveness. Shortterm relative efficacy data for all comparators in the model were taken directly from published meta-analyses, if available, or directly from clinical trials. ${ }^{11,17,20-22,25,28}$ Another strength of this model is the inclusion of disease-specific outcome measures such as cost/SGRQ responder and cost/exacerbation avoided. Other strengths include the model structure that reflects the clinical course of COPD and the conduct of extensive sensitivity analyses to test the robustness of results. Additionally, all costs were independently verified and deemed appropriate by a panel of advisors who tested the real-world application of the assumptions included in the model.

\section{Limitations}

As with all economic models, this cost-effectiveness analysis had several limitations. First, the efficacy measure in the model was CFB to 12 weeks in $\mathrm{FEV}_{1}$, which was the primary endpoint in the IND/GLY 27.5/15.6 $\mu \mathrm{g}$ FLIGHT trials. However, the 12-week $\mathrm{FEV}_{1}$ time point was not available for all comparators and where necessary, efficacy at 12 weeks was derived from published charts as an interim analysis. Second, the CFB in trough $\mathrm{FEV}_{1}$ values used in the model were taken from a single head-to-head study or mixed treatment comparison of all comparators. Data from a single mixed treatment comparison network meta-analysis would make the model more robust, as differences in study designs and patient populations may limit the direct comparability of study outcomes. However, it should be noted that values were placebo adjusted to calculate the marginal efficacy vs placebo in order to control for few differences, such as disease severity of patient population, which may impact both treatment and placebo response rates. Furthermore, the rate of exacerbations for each health state were taken from published literature, with exacerbations at each health state assumed to be constant for all comparators. As such, the model did not consider differences in exacerbation rates among different comparators within the same health state. For simplicity and in alignment with previously developed models in COPD, we did not explicitly account for loss of lung function after specific exacerbation events and instead applied a constant rate of decline in lung function across all patients that was derived from a previous study. ${ }^{19}$ It is assumed that the loss of lung function following exacerbation is captured within this decline. A further limitation of this analysis is the assumption of complete adherence, no switching, and no discontinuation, which does not reflect real-world experience with these therapies. Differentiation of comparators based on real-world effectiveness considering patient adherence may intensify or mediate differences in cost-effectiveness across the comparators; however, in the absence of real-world adherence data, this type of analysis is currently not feasible.

\section{Conclusion}

This analysis found IND/GLY 27.5/15.6 $\mu \mathrm{g}$ to be more costeffective than other commonly used long-acting bronchodilators for the treatment of moderate to severe COPD. As this analysis appears to be the first to compare the cost-effectiveness of the four LABA/LAMA therapies available in the US, it may be of use in informing formulary decision making. As more real-world evidence becomes available, further analysis will be needed to better understand the cost-effectiveness of LABA/LAMA therapies in the real-world setting.

\section{Acknowledgment}

The study was funded by Sunovion Pharmaceuticals Inc. and Novartis Pharmaceuticals Corporation.

\section{Disclosure}

KR was an employee of Sunovion Pharmaceuticals Inc at the time the study was conducted. CD is an employee of Sunovion Pharmaceuticals Inc. JM and AK are employees of Novartis Pharmaceuticals Corporation. LB was an employee of Xcenda LLC when the study was conducted. The authors report no other conflicts of interest in this work.

\section{References}

1. Global Initiative for Chronic Obstructive Lung Disease (GOLD). Global strategy for the diagnosis, management and prevention of COPD; 2017. Available from: http://goldcopd.org/gold-2017-global-strategy-diagnosis-management-prevention-copd/. Accessed February 28, 2018.

2. COPD Foundation. COPD Statistics Across America-How Common Is COPD? Available from: https://www.copdfoundation.org/What-is-COPD/ Understanding-COPD/Statistics.aspx. Accessed March 20, 2018.

3. Mannino DM, Gagnon RC, Petty TL, Lydick E. Obstructive lung disease and low lung function in adults in the United States: data from the National Health and Nutrition Examination Survey, 1988-1994. Arch Intern Med. 2000;160(11):1683-1689.

4. National Center for Health Statistics (US). Health, United States, 2015: With special feature on racial and ethnic health disparities. Available from: https:// www.cdc.gov/nchs/data/hus/hus15.pdf. Accessed November 14, 2018.

5. Wheaton AG, Cunningham TJ, Ford ES, Croft JB; Centers for Disease Control and Prevention (CDC). Employment and activity limitations among adults with chronic obstructive pulmonary disease-United States, 2013. MMWR Morb Mortal Wkly Rep. 2015;64(11):289-295. 
6. Ford ES, Murphy LB, Khavjou O, Giles WH, Holt JB, Croft JB. Total and state-specific medical and absenteeism costs of COPD among adults aged $\geq 18$ years in the United States for 2010 and projections through 2020. Chest. 2015;147(1):31-45.

7. Hasegawa K, Tsugawa Y, Tsai CL, Brown DF, Camargo CA. Frequent utilization of the emergency department for acute exacerbation of chronic obstructive pulmonary disease. Respir Res. 2014;15:40.

8. National Heart LaBI. Morbidity \& mortality: 2012 chart book on cardiovascular, lung, and blood diseases. Available from: https://www. nhlbi.nih.gov/files/docs/research/2012_ChartBook_508.pdf. Accessed May 3, 2015.

9. D'Urzo AD, Rennard SI, Kerwin EM, et al. Efficacy and safety of fixed-dose combinations of aclidinium bromide/formoterol fumarate: the 24-week, randomized, placebo-controlled AUGMENT COPD study. Respir Res. 2014;15:123.

10. Utibron Neohaler (indacterol and glycopyrrolate) [prescribing information]. Marlborough, MA: Sunovion Pharmaceuticals Inc; 2017.

11. Mahler DA, Kerwin E, Ayers T, et al. FLIGHT1 and FLIGHT2: Efficacy and safety of QVA149 (indacaterol/glycopyrrolate) versus its monocomponents and placebo in patients with chronic obstructive pulmonary disease. Am J Respir Crit Care Med. 2015;192(9):1068-1079.

12. Siebert U, Alagoz O, Bayoumi AM, et al. State-transition modeling: a report of the ISPOR-SMDM Modeling Good Research Practices Task Force-3. Value Health. 2012;15(6):812-820.

13. Kerwin E, Ferguson GT, Sanjar S, et al. Dual bronchodilation with indacaterol maleate/glycopyrronium bromide compared with umeclidinium bromide/vilanterol in patients with moderate-to-severe COPD: results from two randomized, controlled, cross-over studies. Lung. 2017;195(6):739-747.

14. Ferguson GT, Karpel J, Bennett N, et al. Effect of tiotropium and olodaterol on symptoms and patient-reported outcomes in patients with COPD: results from four randomised, double-blind studies. NPJ Prim Care Respir Med. 2017;27(1):7.

15. Buhl R, Gessner C, Schuermann W, et al. Efficacy and safety of once-daily QVA149 compared with the free combination of once-daily tiotropium plus twice-daily formoterol in patients with moderate-to-severe COPD (QUANTIFY): a randomised, non-inferiority study. Thorax. 2015; 70(4):311-319.

16. Wilson MR, Patel JG, Coleman A, Mcdade CL, Stanford RH, Earnshaw SR. Cost-effectiveness analysis of umeclidinium/vilanterol for the management of patients with moderate to very severe COPD using an economic model. Int J Chron Obstruct Pulmon Dis. 2017;12:997-1008.

17. Bevespi Aerosphere (glycopyrrolate/formoterol fumarate) [prescribing information]. Wilmington, DE: AstraZeneca Pharmaceuticals LP; 2016.

18. Borg S, Ericsson A, Wedzicha J, et al. A computer simulation model of the natural history and economic impact of chronic obstructive pulmonary disease. Value Health. 2004;7(2):153-167.

19. Celli BR, Thomas NE, Anderson JA, et al. Effect of pharmacotherapy on rate of decline of lung function in chronic obstructive pulmonary disease: results from the TORCH study. Am J Respir Crit Care Med. 2008;178(4):332-338.

20. Cope S, Capkun-Niggli G, Gale R, Jardim JR, Jansen JP. Comparative efficacy of indacaterol $150 \mu \mathrm{g}$ and $300 \mu \mathrm{g}$ versus fixed-dose combinations of formoterol + budesonide or salmeterol + fluticasone for the treatment of chronic obstructive pulmonary disease - a network metaanalysis. Int J Chron Obstruct Pulmon Dis. 2011;6:329-344.

21. Donohue JF, Maleki-Yazdi MR, Kilbride S, Mehta R, Kalberg C, Church A. Efficacy and safety of once-daily umeclidinium/vilanterol 62.5/25 mcg in COPD. Respir Med. 2013;107(10):1538-1546.

22. Dransfield MT, Feldman G, Korenblat P, et al. Efficacy and safety of once-daily fluticasone furoate/vilanterol $(100 / 25 \mathrm{mcg})$ versus twicedaily fluticasone propionate/salmeterol $(250 / 50 \mathrm{mcg})$ in COPD patients. Respir Med. 2014;108(8):1171-1179.

23. Earnshaw SR, Wilson MR, Dalal AA, et al. Cost-effectiveness of fluticasone propionate/salmeterol $(500 / 50 \mathrm{microg})$ in the treatment of COPD. Respir Med. 2009;103(1):12-21.
24. Hurst JR, Vestbo J, Anzueto A, et al. Susceptibility to exacerbation in chronic obstructive pulmonary disease. $N$ Engl J Med. 2010;363(12): $1128-1138$.

25. Karabis A, Lindner L, Mocarski M, Huisman E, Greening A. Comparative efficacy of aclidinium versus glycopyrronium and tiotropium, as maintenance treatment of moderate to severe COPD patients: a systematic review and network meta-analysis. Int J Chron Obstruct Pulmon Dis. 2013;8:405-423.

26. Mahler DA, Baird JC. Are you fluent in the language of dyspnea? Chest. 2008;134(3):476-477.

27. Rutten-van Mölken MP, Oostenbrink JB, Miravitlles M, Monz BU. Modelling the 5-year cost effectiveness of tiotropium, salmeterol and ipratropium for the treatment of chronic obstructive pulmonary disease in Spain. Eur J Health Econ. 2007;8(2):123-135.

28. Singh D, Ferguson GT, Bolitschek J, et al. Tiotropium + olodaterol shows clinically meaningful improvements in quality of life. Respir Med. 2015;109(10):1312-1319

29. Centers for Medicare \& Medicaid Services. Physician fee schedule. Available from: http://www.cms.gov/apps/physician-fee-schedule/ search/search-criteria.aspx. Accessed May 10, 2018.

30. Llor C, Moragas A, Hernández S, Bayona C, Miravitlles M. Efficacy of antibiotic therapy for acute exacerbations of mild to moderate chronic obstructive pulmonary disease. Am J Respir Crit Care Med. 2012; 186(8):716-723.

31. Oostenbrink JB, Rutten-van Mölken MP, Monz BU, Fitzgerald JM. Probabilistic Markov model to assess the cost-effectiveness of bronchodilator therapy in COPD patients in different countries. Value Health. 2005;8(1):32-46.

32. Polsky D, Bonafede M, Suaya JA. Comorbidities as a driver of the excess costs of community-acquired pneumonia in U.S. commerciallyinsured working age adults. BMC Health Serv Res. 2012;12:379.

33. Red Book Online. Truven Health Analytics. 2017. Available from: https://truvenhealth.com/Products/Micromedex/Product-Suites/ Clinical-Knowledge/RED-BOOK. Accessed November 14, 2018.

34. Stanford RH, Shen Y, Mclaughlin T. Cost of Chronic Obstructive Pulmonary Disease in the Emergency Department and Hospital: An Analysis of Administrative Data from 218 US Hospitals. Treat Respir Med. 2006;5(5):5:343-349.

35. Spiriva Respimat (tiotropium bromide) [prescribing information]. Ridgefield, CT: Boehringer Ingelheim Pharmaceuticals, Inc; 2017.

36. Advair Diskus (fluticasone propionate and salmeterol inhalation powder) [prescribing information]. Research Triangle Park, NC: GlaxoSmithKline; 2018.

37. Symbicort (budesonide and formoterol fumarate dihydrate) [prescribing information]. Wilmington, DE: AstraZeneca Pharmaceuticals; 2018.

38. Tudorza Pressair (aclidinium bromide inhalation powder) [prescribing information]. Wilmington, DE: AstraZeneca Pharmaceuticals; 2017.

39. Breo Ellipta (fluticasone furoate and vilanterol inhalation powder) [prescribing information]. Research Triangle Park, NC: GlaxoSmithKline; 2017.

40. Jones PW, Gelhorn H, Wilson H, et al. Responder Analyses for Treatment Effects in COPD Using the St George's Respiratory Questionnaire. Chronic Obstr Pulm Dis. 2017;4(2):124-131.

41. Pharmacy Benefit Management Institute. Prescription Drug Benefit Cost and Plan Design Report 2015-2016. 2015. Available from: https://www.pbmi.com/ItemDetail?iProductCode=2015-2016_ BDR\&Category=BDR. Accessed November 14, 2018.

42. United States Bureau of Labor Statistics. Consumer Price Index AUCMCCU. All Urban Consumers. Medical Care Component. US Bureau of Labor Statistics, Washington, DC; 2012. Available from: http:// data.bls.gov/cgibin/surveymost?cu. Accessed February 10, 2017.

43. Dubois RW. Optimal slices of the healthcare spending pie: can traditional comparative effectiveness research address resource allocation? J Comp Eff Res. 2016;5(6):525-527. 
International Journal of COPD

\section{Publish your work in this journal}

The International Journal of COPD is an international, peer-reviewed journal of therapeutics and pharmacology focusing on concise rapid reporting of clinical studies and reviews in COPD. Special focus is given to the pathophysiological processes underlying the disease, intervention programs, patient focused education, and self management protocols.

This journal is indexed on PubMed Central, MedLine and CAS. The manuscript management system is completely online and includes a very quick and fair peer-review system, which is all easy to use. Visit http://www.dovepress.com/testimonials.php to read real quotes from published authors 